\title{
Ciudad de Panamá, 500 años entre ferias y miserias ${ }^{1}$
}

\section{Olmedo Beluche $^{2}$}

\section{Resumen}

Este artículo realiza un repaso breve de la historia de la ciudad de Panamá, a 500 años de su fundación, partiendo de la aldea indígena primigenia, a la ciudad colonial transitista (función asignada por el mercado mundial al país) fundada por Pedrarias Dávila, pasando por su crisis de los siglos XVIII al XIX, y su restitución de la función transitista con el ferrocarril y el canal, hasta llegar al presente. El articulo acompaña cada etapa de la ciudad con su respectiva fase del desarrollo literario, cada uno con un estilo y una temática propia.

Palabras clave: transitismo, sistema mundo, barroco colonial, romanticismo, modernidad

\section{Summary}

This article briefly reviews the history of Panama City, 500 years after its foundation. It starts from the early indigenous village, to the transitista (function in the global market as a transit country) colonial city founded by Pedrarias Dávila, going through its crisis from the eighteenth to the nineteenth centuries, and its return to the transitista function with the railway and the canal, until the present. The article accompanies each stage of the city with its respective phase of literary development, each with its own style and theme.

Keywords: Transit country, World system, Colonial Baroque, Romanticism, Modernism

1 . Recibido 10/27/2019 - Aprobado 11/28/2019. Conferencia dictada en el V Congreso de Docentes de Español a nivel superior: "500 años de Lengua y Literatura en Panamá", en la Universidad de Panamá, el 18 de octubre de 2019.

2 Profesor titular de Sociología de la Universidad de Panamá. Email: olmedobeluche@hotmail.com 
Te miro a veces, Patria,

como un túnel

de cruces y burdeles, como un golpeado muro de cantina.

Espectros insaciables, cual brujas mitológicas, chupan tu sangre pura, cortan tu sangre humilde, tus manos temblorosas como pétalos José Franco

La ciudad de Panamá cumple 500 años de fundación, que bien pueden ser más, porque este aniversario pasa por alto que, mucho antes que llegara Pedrarias Dávila, ya existía allí una protociudad o aldea indígena, de cuyos habitantes no sabemos casi nada por esa "colonialidad del ser", como diría Aníbal Quijano, por la cual se pretende borrar todo aquello que no sea la cultura que impusieron los colonialistas europeos.

Como si antes de Pedrarias, y del 15 de agosto de 1519, no hubiera nada allí. La verdad histórica es que pocas veces se fundan ciudades o se hacen caminos que las experiencias de generaciones pretéritas no hayan probado como buenos. Las ciudades que se fundan y perduran nunca son completamente nuevas, sino que ya antes ha habido gente ahí.

En la Historia General de Panamá, el propio Alfredo Castillero C. ha dicho: "Los orígenes de la ciudad de Panamá están oscurecidos por una nube de incertidumbres, ambigüedades e imprecisiones. Suele aceptarse como fecha de la fundación de Panamá el 15 de agosto de 1519. Sin embargo, de todas las crónicas y textos de la conquista, la única fuente que respalda esta fecha es la de Pascual de Andagoya".

Hasta el nombre está oscurecido por el mito ¿“abundancia de peces y mariposas”? O, como probablemente nos diría el filólogo kuna, Aristeides Turpana, en realidad cuando los españoles preguntaban dónde estaba el oro, los indígenas les decían "banamá o panamá", que en realidad quería decir: "más allá".

¿Por qué los españoles eligieron este lugar? La versión que ha prevalecido, dada por nuestro principal historiador del período colonial, Alfredo Castillero Calvo, es que era una pequeña aldea de pescadores, y que fue el hambre la que impuso el lugar, ya que aquí se "cosechaban" abundantes almejas.

Pese a lo dicho por Castillero, intriga una cita del cronista Gonzalo Fernández de Oviedo, aparentemente refiriendo palabras del propio Pedrarias: "el cacique que agora es de Panamá se dice Cori. Este e todos sus antepasados son grandes fundidores de oro e maestros en labrarlo e hacen alli muy gentiles piezas; y como todos cuantos caciques hay en su contorno y de lejos de su provincia cuando quieren labrar algunas piezas de oro e facer algunas cosas sutiles van alli, tienen ya por costumbre de gran tiempo decir que el oro que tienen lo traen de Panamá; y así preguntando a cualquier cacique que el oro que tiene de 
donde lo trae, responde que de Panamá. Toda la fama es de Panamá, aunque cójenlo ellos en sus mismas tierras, porque en Panamá no se coje ningún oro ni lo hay".

Si creemos esta versión, no se trataría de una simple aldea de pescadores, sino un pueblo de orfebres, que trabajaban artísticamente el oro de otras regiones porque aquí no había minas. Por ende, el "hambre" que atrajo a los españoles no sería simplemente fisiológica, sino el ansia de riquezas. Voracidad por el oro que nació desde que Cristóbal Colón y sus huestes, durante su cuarto viaje, en la costa caribeña del Istmo de Panamá, se percataron de la abundancia de oro con que se adornaban sus habitantes originarios.

El rey Fernando, "el católico", al ordenar el viaje de Pedrarias y la construcción de una ciudad a orillas del Mar del Sur, lo hizo motivado por dos objetivos que dan cuenta del carácter del sistema mundo capitalista (Wallerstein) que estaba naciendo: la búsqueda de un paso de un mar a otro, para sostener la expansión comercial hacia el oriente; y la búsqueda del oro, agente primordial de la acumulación originaria capitalista europea (Marx), del que el Rey recibiría su "quinto".

La “conquista” del Istmo de Panamá constituyó un paso definitivo en el proceso de concreción de esa primera globalización, de ese sistema mundo capitalista que, con algunas transformaciones persiste hasta el día de hoy. El asentamiento de Santa María La Antigua del Darién, el "descubrimiento" para los europeos del Mar del Sur, y luego la fundación de la ciudad de Panamá, constituyeron el puente necesario del comercio mundial y de las relaciones de dominación imperialistas, que perduran hasta hoy.

Ese año de 1519 fue decisivo en el parto del nuevo "sistema mundo capitalista" (Wallerstein): comenzó la conquista del imperio azteca por parte del sanguinario Hernán Cortes; Magallanes inició su vuelta al mundo, en la que murió ajusticiado por indígenas del Pacífico Sur, pero que concluyó Elcano; un año antes el Rey Carlos I autorizó la "importación” masiva de esclavos africanos al "Nuevo Mundo"; y se fundó a orillas del Pacífico la ciudad de Panamá, como punta de lanza para la conquista del imperio incaico y las tierras de Centroamérica. El mundo se hizo redondo y más chico desde entonces.

Pero no fue una unidad global basada en la equidad, la fraternidad y la concordia, sino todo lo contrario, nació un mundo partido en dos, entre conquistadores y conquistados; entre colonizadores y colonizados; entre dominadores y dominados; entre explotadores y explotados.

El drama que padecieron los habitantes de aquella aldea, de orfebres o pescadores, los habitantes primigenios de Panamá, que fueron primero esclavizados, saqueados, anulados demográficamente y conducidos a la "zona del no-ser", fue el mismo destino que tocó a decenas de millones en todo el mundo, gracias a ese "gigante de barro y sangre" (Marx) cuyo parto pasó por aquí, el sistema capitalista mundial. 
Así tenemos que la ciudad colonial fundada por Pedrarias fue la ciudad "tansitista", no solo porque por aquí pasaron mercaderías, personas, oro y plata, sino porque da cuenta de un modelo social que se impuso, por el cual los múltiples caminos que unían el Caribe y el Pacífico fueron sustituidos por un solo eje, Panamá - Nombre de Dios, o Panamá - Portobelo, o Panamá - Colón, controlado y al servicio de una potencia extranjera, al cual se supeditó la vida y la economía de todos sus habitantes (Guillermo Castro).

Los primeros 150 años de la ciudad, llamada La Vieja, hasta que muriera calcinada a consecuencia de una mala decisión tomada por el pavor ante la inminente llegada del pirata Henry Morgan, no fueron como lo cuenta la leyenda oficial, todo lleno de oro refulgente, ferias y prosperidad. No. También la ciudad padeció hambrunas reiteradas producto de ese determinismo "transitista" por el cual aquí no se producía casi nada y todo lo que se comía se importaba.

Desabastecimiento que se elevaba a verdaderas crisis y "hambrunas" cuando la amenaza de la piratería forzaba a los barcos a quedarse en sus puertos. Castillero marca los siguientes años como críticos en la provisión de alimentos: 1570-71, 1615, 1625 y esporádicamente en las décadas de 1640, 1650 y 1660.

Pese a las miserias, hubo cultura aquí. Hubo una literatura que hoy podríamos llamar "panameña", aunque no por entonces porque caeríamos en el anacronismo. Dejando de lado, los cantos épicos y sacros de nuestros ancestros precolombinos, podemos preguntarnos, ¿Cuándo empezó la literatura en Panamá? Podría ser con el propio Bartolomé de las Casas, que dicen que nunca estuvo en Panamá, pero que su "Brevísima relación de la destrucción de las Indias” (1552) refiere los trágicos hechos acaecidos aquí.

Tal vez podría ser antes, cuando Gonzalo Fernández de Oviedo, que sí estuvo en Panamá en la época de Pedrarias, publicó su "Historia general y natural de las Indias, islas y tierra firme del mar océano" (1535), que tampoco escribió aquí, pero que también aborda muchos de los sucesos fundacionales.

Un siglo más tarde, ya florecían los poetas en Panamá. En 1638, catorce bardos de entonces dedican sus versos a un gran poema elegíaco post mortem al gobernador Enrique Enríquez de Sotomayor, publicado bajo el título de "El llanto de Panamá". Una colección de 42 poemas y sus autores a los que Antonio Serrano de Haro calificó como "la generación barroca panameña de 1638". Su principal autor, Mateo Ribera, y probablemente la mayoría o todos los otros, había nacido en Panamá, como nos lo revela Rommel Escarreola.

Poco después se escribiría un gran poema épico que describe las luchas de los conquistadores y las resistencias de los kunas en el istmo, escrito por un manchego, Juan Francisco de Páramo y Cepeda, en el más puro y oscuro estilo barroco "Alteraciones del Dariel” (1697). Poema recién descubierto por Carlos Gastezoro en 1956, al que Gloria Guardia atribuye el 
mérito de que "inaugura una realidad: la del Istmo de Panamá" al que Héctor Horjuela eleva y compara con "La Araucana".

Destruida Panamá "La Vieja”, con el incendio y la toma de Morgan en 1671, su hija, Panamá "La Nueva", fundada el 21 de enero de 1673, tuvo mejor suerte con los abastecimientos y no pudo nunca ser tomada nuevamente por los piratas. Sin embargo, fue una ciudad que nació dividida por las murallas, separando a sus clases sociales: los criollos y gachupines, con sus esclavos domésticos dentro de ella; las llamadas castas, libertos, indígenas, negros, fueron excluidos de la ciudad y condenados a vivir en su entorno extramuros.

Además del "apartheid" social, la nueva ciudad tuvo un inicio difícil. Durante cien años languideció agotada por los nuevos incendios y por la desaparición de las Ferias de Portobelo, la crisis del "transitismo", y el cambio de la ruta del oro y la plata hacia Buenos Aires, hoy capital de la Argentina.

La ciudad se vació hasta tener menos de 4,000 habitantes. Los que no se fueron a otras partes más prósperas del imperio español emigraron al "interior" del Istmo. Las clases altas fundaron haciendas autárquicas, porque no había mercados a los cuales vender. Muchos de sus habitantes fundaron los pueblos que hoy constituyen nuestras provincias, y se mudaron a ellos. La crisis de la ciudad de Panamá y del transitismo duró un siglo, entre 1740 y 1850 aproximadamente.

Durante todo el período colonial, y buena parte del período colombiano, los habitantes del resto del Istmo no siempre se sintieron identificados con la ciudad de Panamá. Tal es el caso que, durante este tiempo, "panameños" solo lo eran los habitantes de la ciudad. El resto eran, en todo caso "istmeños" y otros "veragüenses".

A pesar de las miserias, también en este período hubo literatura panameña, por no mencionar otras manifestaciones culturales. Rodrigo Miró nos habla de Víctor de la Guardia y Ayala y su obra teatral "La política del mundo". Además, los poetas romanticismo panameño Manuel María Ayala, Tomás Miró Rubini, José María Alemán, de las novelas históricas de Gil Colunje, Martín Feuillet, Jerónimo de la Ossa y Amelia Denis de Icaza, aunque los tres últimos pertenecen a la Panamá reinserta en el transitismo de la segunda mitad del siglo XIX.

La ciudad nueva viene a recuperarse a mediados del siglo XIX, cuando el proceso de surgimiento de Estados Unidos como potencia capitalista nos colocó en su mapa, gracias a la necesidad que tenía de colonizar rápidamente la California que le había arrebatado por la fuerza a México en 1847. De manera que resurgió el transitismo, esta vez controlado por los norteamericanos, colocando la ciudad en el eje del "Gold Rush".

Pero el renacimiento del Camino de Cruces, las recuas de mulas y los bongos duró poco, pues fue prontamente suplantado por la Panama RailRoad Company, la cual construyó sus propios rieles, estaciones y una nueva ciudad en el caribe que sustituyó a Portobelo, la ciudad de 
Colón, que pasó a ser el otro polo del tránsito. La ciudad se reanimó, pero sus habitantes perdieron el control sobre el negocio transitista, pasando a ser espectadores al borde del camino por el que pasaba un comercio del que se beneficiaban poco. El Incidente de la Tajada de Sandía expresó en cierta forma ese descontento.

La construcción del Canal Francés (1880-88) y del Canal Norteamericano (1904-1914) mantuvo la importancia transitista de la ciudad, pero con la pérdida del control de la ruta y del comercio. Sólo beneficios a cuenta gotas se derramaban del vaso de la riqueza del capitalismo financiero naciente. Aunque uno de los principales beneficios que se obtuvo no fue muy apreciado al principio: el aporte cultural y humano de la masa de trabajadores migrantes que llegaron, que hicieron de la ciudad una metrópoli cosmopolita.

Panamá se convirtió de nuevo en una ciudad escindida. Esta vez estaba dividida por una cerca de ciclón, y no por un muro, que separó a los habitantes de la Zona del Canal, que vivían la prosperidad que el imperialismo yanqui les podía garantizar, lejos del resto de los panameños que habitaban "este lado de la cerca". Pero a su vez, dentro de la propia "zona" se aplicaba un "apartheid" que separaba a los "zonians" blancos, de los "coloreds", no solo salarialmente (gold roll y silver roll), sino también en barrios segregados (Pedro Miguel, Paraíso).

Es en este periodo traumático, marcado por la forma cuestionable de la separación de Colombia y la pérdida del territorio canalero a mano de los yanquis, de inicios del siglo XX, cuando el debate intelectual, la producción cultural y literaria se concentra en el dilema de: ¿quiénes somos? ¿Somos una nación?

Aquí es donde Luis Pulido Ritter (en "Filosofía de la nación romántica”) señala que nace un nacionalismo que es una "crítica antimoderna de la modernidad", que busca fijar la identidad pero anclada en el pasado, en el "interior" de trazos coloniales, por oposición a la ciudad de Panamá cosmopolita pero degradada.

Luis Pulido Ritter establece que hay en la tradición intelectual panameña, de diferentes orígenes sociales y políticos, un enfoque "romántico" sobre la nación, que nace desde Belisario Porras (Carta a un amigo, 1904); sigue con Ricardo J. Alfaro (al fundar la Academia Panameña de la Lengua, 1926); pasa por los poetas republicanos (Ricardo Miró, Gaspar O. Hernández) criticados por Roque J. Laurenza en su célebre ensayo (Los poetas de la generación republicana, 1933); sigue por los novelistas de mitad de siglo (Ramón H. Jurado, Joaquín Beleño, Octavio Méndez Pereira y José I. Fábrega); y ensayistas como Diógenes De La Rosa y Eusebio A. Morales; adquiere su dimensión filosófica con Ricaurte Soler, Isaías Gracía y Diego Domínguez Caballero; para convertirse en filosofía de la historia con Carlos Gasteazoro.

Por ejemplo, la novela Crisol (1936) de José I. Fábrega, “en la que los personajes negros que llevan la fatalidad de ser ladrones $y$, además, eran estéticamente feos y torcidos moralmente". 
Los intelectuales panameños verían con "desconfianza", con "sentimiento de inferioridad", esa modernidad de la que se había excluido al país al quedar en manos extranjeras. Los que habían abrazado la esperanza de un futuro mejor en la modernidad, como el pragmático Méndez Pereira, ya estaban decepcionados en la tercera década y no esperaban nada positivo de ella. Según Pulido, esto los llevó a caer en una especie de "introspección nacional" pesimista que asocia a la novela El Desván, de Ramón H. Jurado, de la que toma la frase con la que cierra el libro: "yo nací en el miedo (...) Es curioso: la gente tiene miedo de pensar y está viva, viva como yo".

Frente a un presente, entre oprobioso e incierto, la intelectualidad panameña se dispuso a construir el mito fundacional de la nación. La novela se funde con el mito en Octavio Méndez Pereira, con su Núñez de Balboa. El Tesoro del Dabaibe. Esta es la parte más jocosa y a la vez más aguda del libro de Pulido Ritter: "La nación necesitaba un héroe. Un guerrero. Un héroe que encontrara como Jesucristo su realización en la muerte. Si Jesucristo fue crucificado, Vasco Núñez fue decapitado... Pero a diferencia de Jesucristo que era un asceta, nuestro héroe necesitaba una mujer en el trópico: Anayansi".

Fueron los descendientes de ese coctel genético producido por los migrantes afroantillanos, mezclados con las "castas" heredadas del colonialismo español, a los que las clases oligárquicas no querían al inicio de la república, y querían expulsar como "razas indeseables" (Constitución Política de 1941), quienes que lucharían incansable y generacionalmente contra el sistema excluyente de la Zona y por la soberanía en todo el territorio, bajo el grito de "Una sola bandera, un solo territorio", cuyo clímax fue la gesta Heroica del 9 de Enero de 1964 (Patricia Pizzurno).

Ese acontecimiento marcó la historia de la ciudad y del país en dos épocas, iniciando el proceso que llevaría a la desaparición de la Zona del Canal y la recuperación de la soberanía, por intermedio de los Tratados Torrijos Carter de 1977. El último día del siglo XX marcaría ese final.

El siglo XX cuajó la identidad de la ciudad junto con la identidad nacional en un proceso complejo de lucha contra la aniquilación política, económica y cultural a que nos quería someter el colonialismo norteamericano. Una ciudad construida por migrantes, tanto del interior como del exterior. Miles de campesinos pauperizados y sin tierra migraron de las provincias. Los trabajadores provenientes de otros países de la región, aunque en menor medida que durante la construcción canalera, no pararon de llegar.

Decenas de miles harían aquí su morada viviendo sus vicisitudes, sus momentos de prosperidad y los de crisis; sus fiestas y sus duelos; sus traumas políticos y los dramas sangrientos, como la invasión del 20 de Diciembre de 1989, con sus centenares y miles de muertos y heridos. 
Panamá La Vieja fue una de las víctimas de la invasión, ya que en el entorno de su plaza mayor se hallaba enclavado un cuartel de las Fuerzas de Defensa, lo que dice mucho de la indiferencia de nuestros gobiernos hacia el patrimonio histórico; así que el área fue bombardeada y abaleada por los helicópteros norteamericanos, antes de dejar caer allí un grupo de paracaidistas. Así que podemos afirmar que nuestra ciudad fundacional ha recibido la agresión militar de los piratas ingleses y de los piratas norteamericanos.

Así como la separación de Colombia y el Tratado Hay-Bunau Varilla constituyeron el trauma que marcó la reflexión de la intelectualidad de principios del siglo XX, la invasión de 189 es el trauma que obliga a pensar sobre nuestro presente y futuro a los literatos de este inicio del siglo XXI.

La invasion ha sido abordada por autores como: Manuel Orestes Nieto, Roberto Luzcando, Ramón Oviero, Pablo Menacho, Arístides Martínez Ortega, Arysteides Turpana, Xavier Collado, Consuelo Tomás, Bertalicia Peralta, Moisés Pascual, Indira Moreno, Eyra Harbar, Leoncio Obando, Lucy Chau, Alex Mariscal, Jilma Noriega de Jurado, Enrique Chuez, Moravia Ochoa, Bertalicia Peralta, Mario Augusto Rodríguez, Pedro Luis Prados, Porfirio Salazar, Héctor Collado, Dayra Miranda, David Robinson, Mario García Hudson, José Carr, Juan Gómez, Raúl Leis, Dimas Lidio Pitty, Tristán Solarte, Martín Testa, Chuchú Martínez, Víctor Manuel Rodríguez, Pedro Rivera, Carlos Changmarín, Juan David Morgan, Itzel Velázquez, Víctor Manuel Rodríguez, Rey Barría, Félix Armando Quirós, Carlos Jiménez, José Franco, Octavio Tapia, Javier Stanziola, Giovanna Benedetti, Claudio de Castro, Julio Yau, Carlos Fong, entre tantos.

Quinientos años después, la ciudad ha cambiado, pero sigue siendo la misma. La reconocemos por sus marcas de nacimiento, como la torre de Panamá La Vieja, la bahía, el casco antiguo; pero ella también ha cambiado, ya no hay almejas en su entorno, por ejemplo. Su fisonomía cambió bastante, especialmente en el lapso de esta última generación.

Una parte de ella son sus enormes y vistosas edificaciones plantadas a lo largo de la Cinta Costera y su Skyline (¡Ups, perdón por el anglicismo!) que es lo que solo quieren ver algunos. Pero también son sus profundas arrugas en barrios populares que se extienden de este a oeste y hacia el norte, con sus calles sucias, sus ineficientes servicios de agua potable, alcantarillado y recolección de basura, con sus escuelas y hospitales en mal estado.

La ciudad, en últimas, no son sus edificios y sus calles, sino sus habitantes. Algunos de ellos pillos de temer, políticos corruptos y comerciantes ávidos; pero la mayoría aplastante de ese pueblo panameño se caracteriza por ser trabajador, abnegado, solidario, amistoso y feliz, a pesar de los pesares.

\section{Referencias}

Araúz, Celestino; Pizzurno, Patricia. (1997). El Panamá Hispano (1501-1821)”. Tercera Edición. Panamá: Diario La Prensa. 
Beluche, Olmedo. (2017). Historia agraria y luchas sociales en el campo panameño. Panamá: Colección de Estudios Interdisciplinarios. CIFHU, Universidad de Panamá.

Castillero, Alfredo. (1995). Conquista, Evangelización y Resistencia. Instituto Nacional de Cultura. Panamá: Colección Ricardo Miró.

Castillero, Alfredo. (2004). Historia General de Panamá. Panamá: Comité Nacional del centenario.

Castro H., Guillermo. (2007). El agua entre los mares. La historia ambiental en la gestión del desarrollo sostenible. Panamá: Editorial Ciudad del Saber.

Cooke, Richard y Sánchez Herrera, Luis Alberto. (2004). “El Panamá prehispánico”. En: Historia General de Panamá. Volumen I, Tomo I. Panamá: Comité Nacional del centenario.

Escarreola Palacios, Rommel. (2019). "Una mirada histórica a la literatura panameña: el caso de El Llanto de Panamá’. El Siglo. Panamá, 19 de agosto.

Oviedo, Gonzalo Fernández de. (1995). Sumario de la Natural historia de las Indias. Colección "Fabio Lozano y Lozano". Santafé de Bogotá. (recuperado el 10 de octubre de 1 2019 en http://www.worldcat.org/title/sumario-de-la-natural-historia-de-lasindias/oclc/465694670).

Pizzurno, Patricia. (2016) El miedo a la modernidad en Panamá 1904 - 1930. Panamá: Editorial Cultural Portobelo.

Pulido R., Luis. (2007. Filosofía de la nación romántica (Seis ensayos críticos sobre el pensamiento intelectual y filosófico en Panamá, 1930-1960). Colección Ricardo Miró. Premio Ensayo.

Sibaja, Luis Fernando. (2006). El cuarto viaje de Cristóbal Colón y los orígenes de la provincia de Costa Rica. Costa Rica: EUNED. San José,.

Wallerstein, Inmanuel. (2010). El Moderno Sistema Mundial I. México: Editorial Siglo XXI. 